\title{
RAÇA, IDENTIDADE E PÓS-MODERNIDADE EM STUART HALL: contrapontos com o debate de Paul Gilroy
}

\author{
Pedro de Castro Picelli ${ }^{1}$
}

\begin{abstract}
Resumo:
O presente ensaio busca, a partir da leitura de textos de Stuart Hall, discutir a articulação dos conceitos de raça e identidade presentes em partes relevantes da obra deste autor. Irá se adotar como fragmento principal de discussão o texto A Identidade Cultural na Pós-Modernidade, escrito em 1992 e publicado como capítulo em Modernity and its futures (HALL, HELD e MC GREW, 1992). Como contraponto argumentativo e uma maneira possível de serem interpelados os argumentos de Hall, volta-se também a atenção para a exposição do debate e reflexão dos mesmos conceitos na obra de Paul Gilroy, centralmente em O Atlântico Negro, onde este autor reelabora o problema da ideia de modernidade e a articula à temática debatida neste ensaio. Adota-se como plano de fundo do debate, a reflexão de ambos os autores sobre os pressupostos e consequências da definição do que é ser moderno, uma discussão clássica no campo das ciências sociais, e como esta própria definição informa a argumentação que Hall e Gilroy constroem sobre raça, identidade e a relação entre elas. Em linhas gerais, este ensaio argumenta que Hall analisa a transformação destes conceitos na "pós-modernidade" como uma transformação da própria modernidade. Gilroy, por sua vez, a reconceitualiza para discutir raça e identidade, rompendo com alguns paradigmas do que se foi construído como moderno.
\end{abstract}

Palavras-chave: raça, identidade, pós-modernidade, Stuart Hall; Paul Gilroy

\begin{abstract}
:
The present essay seeks, from the reading of texts by Stuart Hall, to discuss the articulation of the concepts of race and identity present in relevant parts of this author's work. The Cultural Identity in Postmodernity, written in 1992 and published as a chapter in Modernity and its Futures (HALL, HELD and MCGREW, 1992), will be adopted as the main discussion fragment. As anargumentative counterpoint and a possible way of questioning Hall's arguments, attention is also drawn to the discussion and reflection of the same concepts in Paul Gilroy's work, centrally in The Black Atlantic, where this author reworked the problem of the idea of modernity and articulates it with the theme debated in this essay. The debate is based on the assumptions and consequences of the definition of what is to be modern, a classic discussion in the field of social sciences, and how this definition informs the argument that Hall and Gilroy build on race, identity and the relationship between them. Broadly speaking, this essay argues that Hall analyzes the transformation of these concepts into "postmodernity" as a transformation
\end{abstract}

\footnotetext{
${ }^{1}$ Graduado em Ciências Sociais pela Universidade Estadual de Campinas (Unicamp) e mestrando em Sociologia pela Unicamp. E-mail: pedrocastropicelli@gmail.com.
} 
of modernity itself. Gilroy, in turn, reconceptualizes him to discuss race and identity, breaking with some paradigms of what was built as modern.

Keyword: race, identity, pos-modernity, Stuart Hall, Paul Gilroy 


\section{Introdução}

O presente ensaio busca refletir sobre o modo como as categorias raça e identidade são articuladas por Stuart Hall, dentro de um contexto denominado pelo autor como pósmodernidade, adotando como contraponto ideias propostas por Paul Gilroy. Hall, jamaicano nascido em Kingston, foi um dos autores de maior destaque dentro da área que ficou conhecida como Estudos Culturais, desenvolvida centralmente no Reino Unido. $\mathrm{O}$ autor, com o aumento da tensão racial e política jamaicana, muda-se para a Inglaterra em 1951, ao ser contemplado com uma bolsa de estudos na Universidade de Oxford. Cabe frisar que Hall é um dos tantos sujeitos que fizeram parte da larga escala migratória caribenha à Europa. Certamente, esse deslocamento e as dificuldades para inserção social informaram grande parte dos argumentos que iremos expor aqui. Com o passar do tempo, seus laços com os sujeitos negros imigrantes na Europa se estreitaram. Em constante conflito entre o lugar de onde vinha e aquele onde estava, Hall viu nesse conflito latente potencialidade para refletir sobre os modos como essas identidades seriam absorvidas pelos movimentos de esquerda. Em 1960, torna-se o editor da New Left Review. É neste contexto que Hall nota que as identidades, forjadas a muito custo pela modernidade, começam a se reconfigurar dentro de um cenário totalmente diferente. $\mathrm{O}$ aspecto central desta transformação é o fato de a nação não ser mais a mobilizadora principal das formações identitárias. As identidades, portanto, fragmentam-se de forma nunca vista anteriormente.

Em linhas gerais, as ideias de Hall e de parte dos autores dos Estudos Culturais se relacionam com parte da discussão gramsciana sobre hegemonia e cultura. Dentro deste cenário, o autor- assim como os Estudos Culturais- dá destaque às questões que relacionam a linguagem enquanto operadora das estruturas de poder, da política, das próprias instituições e, principalmente, da cultura. Esse enfoque é fundamentado pelo fato de Hall afirmar a cultura como "local crítico da ação social e de intervenção, onde as relações de poder são estabelecidas e potencialmente instáveis". Ela também é o local em que podem ser observadas as rupturas promovidas pela pós-modernidade e o local por onde o autor busca entrar no debate clássico das ciências sociais sobre os paradigmas e paradoxos da modernidade. Paul Gilroy, o autor com quem construiremos o contraponto com Hall, enxerga os mesmos problemas sob novas lentes.

Paul Gilroy, britânico nascido em Londres, será lido aqui através de O Atlântico Negro como uma das possíveis críticas ao recorte realizado por Hall e por alguns autores dos Estudos Culturais, do qual também fazia parte. Ao olhar para a questão da modernidade e para o modo 
como ela ajuda a forjar a identidade dos indivíduos, Gilroy observa que a fragmentação das identidades analisadas por Hall não é específica da transição para a pós-modernidade. Tal afirmação é feita quando o autor londrino busca reconstruir, a partir do tráfico de escravos pelo Atlântico, as formas pelas quais as identidades foram forjadas. Para seu argumento, a identidade, como um amálgama cultural moderno, nunca existiu. Ela foi fruto de deslocamentos e construções dentro do trânsito atlântico entre distintos países e continentes. Portanto, a pósmodernidade não existe e, para Gilroy, ela é um deslize do analista que busca construir sua análise desconsiderando essa potencialidade do próprio caráter transitório da modernidade. Raça, então, é um fruto desse deslocamento de sujeitos e experiências.

Para realizarmos o objetivo deste ensaio, iremos recorrer a duas obras. A primeira é $A$ Identidade Cultural na Pós-Modernidade (HALL, 2015), onde o autor faz um compilado de seus principais argumentos sobre algumas categorias fundamentais utilizadas em outras obras, dentre elas raça e identidade. A segunda é O Atlântico Negro (GILROY, 2012), obra na qual Gilroy reconstrói o conceito de modernidade e, a partir dela, elabora novas relações possíveis para as categorias que nos interessam neste ensaio. Acreditamos que a reflexão aqui apresentada se faz necessária à medida em que os debates sobre raça e identidade assumem centralidade em algumas pautas nacionais, como a implementação de cotas étnico-raciais nas universidades públicas brasileiras. Além disso, buscaremos sistematizar o debate de ambos os autores contribuindo para a formulação de novos questionamentos que venham a surgir com o contato com as obras originais e comparações possíveis entre as argumentações ${ }^{2}$.

\section{Caminhos de Stuart Hall}

Em A Identidade Cultural na Pós-Modernidade (HALL, 2015), Stuart Hall se propõe a realizar um debate a partir de discussões postas anteriormente por um campo sociológico que conduziu, de forma heterogênea, seus estudos pelo tema das mudanças sociais. Estas foram chamadas, principalmente pela sociologia britânica e americana, globalização ou mundialização e, colocaram-se como problema teórico basilar à existência de uma pretensa pósmodernidade. Escrito em 1992 como capítulo da obra Modernity and its futures, organizada por Stuart Hall, David Held e Tony McGrew, e intitulado originalmente como "The question of cultural identity”, este texto foi posteriormente publicado como livro em 1997, já sob o título

\footnotetext{
2 Alguns trabalhos já lidaram comparativamente com os argumentos e obras destes autores. Ver nas referências deste texto: COSTA (2006), SANTOS (2002), GOMES (2016).
} 
A Identidade Cultural na Pós-Modernidade. O texto se caracteriza por ser um debate teórico onde Hall expõe suas principais categorias analíticas e deixa em primeiro plano o argumento que transcorre em grande parte de sua obra.

Este debate apresenta como interlocutores uma gama de autores, como François Lyotard, Anthony Giddens, Ulrich Beck, entre outros, que se preocuparam em compreender as principais mudanças na experiência social que os processos da globalização colocaram em evidência. Contudo, o argumento central que Hall se preocupa em analisar tem início com a construção de uma ideia de nação como uma unidade orgânica em si, onde cada "povo" se funda na possibilidade de possuir um caráter particular. O Estado passa a materializar, portanto, seus habitantes. Surge o Estado-nação e com ele o problema da cultura como identidade. A cultura, entendida como um universo simbólico que abrange diferenças sociais em um determinado momento histórico, promove a "unificação dos distintos", que passam a partilhar de totalidades. Assim, como afirma Pierre Vilar (1978), o povo-nação representa interesses comuns contra os interesses particulares e o bem comum contra o privilégio. Então, se os indivíduos se diferenciam pela origem de classe ou posicionamento geográfico, a cultura forja uma consciência coletiva que vincula os indivíduos uns aos outros (ORTIZ, 2013, p.612).

Esta partilha de totalidades e de interesses comuns é forjada e consolidada historicamente na modernidade pela promoção de políticas que estimulem a integração entre os membros de uma mesma nação. Esta forja é sintetizada pelo Estado moderno, permitindo que haja a exclusão daqueles que não se encaixam nos padrões tidos como nacionais. Uma dessas políticas se realiza, por exemplo, pela instauração de uma língua oficial em um país e pelo ensino institucionalizado da mesma. A cultura, que agora se constrói nacionalmente e associa principalmente identidade à nacionalidade, assume para si a tarefa de unificação. Esta se realiza a partir da criação de identidades culturais, dos processos de transitoriedade espacial e temporal propiciados pela modernidade. Como nos sugerem os autores citados acima, servindo de ponto de partida para o debate de Hall, a modernidade, ao passo que forja o surgimento da nação, traz com ela a permissão para que as coisas assumam mobilidade no tempo e no espaço.

A modernidade, então, como força criadora de novos modos de relações sociais, proporciona a necessidade de reconhecimento entre indivíduos, ao mesmo tempo em que sublima barreiras de troca simbólicas e materiais entre distintas culturas. Cabe, então, à cultura nacional tentar manter o mínimo de organicidade dentro do Estado-Nação, que se constrói na modernidade enquanto área geográfica de unidade política incorporada à ideia de um conjunto 
culturalmente coeso. Contudo, o desenrolar da modernidade e seu exacerbamento podem promover mudanças na maneira como a questão da identidade é posta. É do questionamento do argumento apresentado por estes intelectuais que Hall constrói seu trabalho: existe uma crise de identidade? Se existe, em que consiste essa crise e em que direção ela está caminhando? A priori, o autor constata que a própria questão da "identidade" tem sido extensamente discutida na teoria social e que o argumento central indica que

\begin{abstract}
“(...)as velhas identidades, que por tanto tempo estabilizaram o mundo social, estão em declínio, fazendo surgir novas identidades e fragmentando o indivíduo moderno, até aqui visto como sujeito unificado. Assim a chamada "crise de identidade" é vista como parte de um processo mais amplo de mudança, que está deslocando as estruturas centrais das sociedades modernas e abalando os quadros de referência que davam aos indivíduos uma ancoragem estável no mundo social” (HALL, 2015, p. 9).
\end{abstract}

Caso esta hipótese seja verdadeira, afirma o autor, põe-se como objetivo do livro se voltar para questões que promovam a reflexão sobre o que se quer dizer com esta crise de identidade. Mais ainda, que acontecimentos dariam bases para sustentação de tal argumento e quais são suas consequências potenciais. Desta maneira, os argumentos se dividem em duas etapas pelo livro: a primeira é apontar para as mudanças históricas que os conceitos de identidade e sujeito apresentam. A segunda tenta dar conta de como estas alterações se relacionam com as identidades culturais. Ou seja, "daqueles aspectos de nossas identidades que surgem de nossos pertencimentos a culturas étnicas, raciais, linguísticas, religiosas e, acima de tudo, nacionais" (ibid, p.9). O argumento central do autor é simpático à afirmação de que as identidades modernas estão sendo "descentradas, fragmentadas ou deslocadas". Dito de outra maneira, esse descentramento se ancora num tipo diferente de mudança estrutural que transforma as sociedades modernas no final do século XX. Esta mudança age fragmentando "as paisagens culturais de classe, gênero, sexualidade, etnia, raça e nacionalidade" (HALL, 2015) que anteriormente se apresentavam como sólidas localizações dos indivíduos sociais. Perde-se, portanto, um "sentido de si" estável promovendo o deslocamento do indivíduo de seu mundo social e cultural e de si próprio. Decorrência deste argumento é a possibilidade de nos perguntarmos se não é a própria modernidade que está sendo transformada ou se conceitualizamos a modernidade de uma maneira equivocada.

\title{
Hall, (pós) modernidade e identidades
}

Stuart Hall afirma existirem historicamente três concepções distintas de identidade: a) sujeito do Iluminismo, b) sujeito sociológico e c) sujeito pós-moderno. O sujeito do Iluminismo 
se caracterizaria por ser um indivíduo totalmente "centrado, dotado das capacidades de razão, de consciência e de ação" (ibid, p.10) Este indivíduo possuiria em si uma essência que carregaria consigo ao longo da vida. Nota-se, assim, uma perspectiva individualista da composição deste sujeito. O segundo tipo, o sujeito sociológico, forma-se a partir da complexidade que o mundo moderno adquire. Assim o indivíduo passa a se construir e construir suas concepções identitárias a partir da relação com outros sujeitos e experiências. A concepção de indivíduo deixa de ser autônoma e autossuficiente para se constituir a partir da relação entre o "eu" e a "sociedade", ou, de outra maneira, entre o "interior" e o "exterior", sendo a identidade uma costura do sujeito à estrutura. Contudo, e aqui se encontra o argumento central do texto, são exatamente estas últimas características que estão em transformação e dão conta do que o autor chama de sujeito pós-moderno. Ou seja, do sujeito que não mais possui uma identidade unificada e estável, mas sim fragmentada e composta por várias identidades, por vezes contraditórias e não resolvidas. Assim, prossegue Hall (2015, p.11), “o próprio processo de identificação [...] tornou-se mais provisório, variável e problemático", tornando a identidade uma "celebração móvel", "formada e transformada continuamente"

Postas as três concepções de sujeito que Hall trabalha em seu argumento, o autor jamaicano passa, a partir de referências claras de seus interlocutores, a organizar o conceito de modernidade com que opera seu raciocínio. Partindo de Karl Marx em O Manifesto Comunista, o autor aponta para os processos de modernidade como o permanente revolucionar da produção e o abalar ininterrupto de todas as constituições sociais. Assim, tudo o que se solidificou se desmancharia no ar. A partir desta definição, Hall explora os conceitos de "tradição" e "modernidade" em Anthony Giddens para argumentar que a mudança, embora rápida e abrangente, se faz de maneira reflexiva iluminada pelo seu passado. Desta forma, o ritmo e o alcance dela se consolidam a partir da reelaboração de categorias como espaço e tempo, a partir de rompimento e reinserção de práticas tradicionais. Dito de outra maneira, a partir de outro interlocutor, David Harvey, a modernidade "não seria apenas um rompimento impiedoso com toda e qualquer condição precedente". Ela seria marcada, então, como "um processo sem fim de rupturas e fragmentações internas no seu próprio interior" (HARVEY, 1989; apud HALL, 2015, p.13).

Embora os dois últimos autores recorridos por Hall apresentem leituras diferentes da natureza da mudança no mundo pós-moderno, ambos marcam suas ênfases na descontinuidade e deslocamento que tais processos apresentam nas experiências sociais do século XX. A partir 
do exemplo do julgamento ocorrido em 1991 na Suprema Corte Americana, comandado pelo juiz negro Clarence Thomas (de posições políticas conservadoras), acusado de assédio sexual por uma mulher negra, Hall busca articular aquilo que chama de "jogo das identidades". Ou seja, como os cruzamentos identitários se articulam e passam a não mais encontrar bases singulares de sustentação, mas sim bases "rivais e deslocantes". Para o autor, este seria um dos sintomas da morte do sujeito moderno centrado, uno e coerente que a época moderna fez construir. Assim, dá-se a morte do sujeito cartesiano, indivisível e soberano, que tem origem no século XVIII, e também a morte do sujeito mais social e biologizado do século XIX.

A afirmação de que estes sujeitos foram descentrados encontra base em cinco grandes avanços na teoria social e nas ciências humanas ocorridos no pensamento no período da “modernidade tardia" (Hall, 2015), ou seja, a partir da segunda metade do século XX. São eles: 1- a leitura althusserianada obra de Marx, 2- a teoria do inconsciente de Freud, 3- os estudos de linguística estruturalista de Ferdinand Saussure, 4- a obra de Michel Foucault e 5- o impacto das teorias e movimentos feministas. Para Hall, estes avanços sinalizaram para os efeitos "profundamente desestabilizadores" que atingiram o modo como sujeito e identidade são contextualizados. Desta maneira, o argumento do autor segue para outra direção. Após sinalizar o que quer dizer com o fim e descentramento do sujeito moderno, o autor passa a refletir sobre a questão de como o sujeito fragmentado é colocado a partir de suas identidades culturais que agora não são mais centralizadas a partir de culturas e identidades nacionais.

O argumento da modernidade é, de certa forma, repensado por Hall a partir de novas categorias. Como afirma o próprio autor, "as identidades não são coisas com as quais nós nascemos, mas são formadas e transformadas no interior da representação." (ibid, p.30). Ou seja, a ideia de nação se sustenta por ser uma comunidade simbólica que consegue contribuir para a criação de uma cultura nacional, pretensamente homogênea, que se torna característica chave da industrialização e um dispositivo da modernidade. Forma-se, então, aquilo que Benedict Anderson chama de nação como "comunidade imaginada". Assim, este autor questiona: como se conta a narrativa da cultura nacional? Em primeiro lugar, há a narrativa da nação a partir de experiências partilhadas. Depois se dá ênfase às origens e tradições, a partir de um mito fundacional e um povo autêntico e puro. Tais procedimentos, como afirma Hall, não são propriamente tão modernos, pois se encontram na ambiguidade de colocar as identidades entre o passado e o futuro. Assim, articulam a ideia de nação como fonte de 
significados culturais, foco de identificações e sistema de representações a partir da ativação de memórias do passado, do desejo por viver em comunidade e pela perpetuação da herança.

Entretanto, a própria ideia de formação de nação não leva em consideração que ela se forma a partir de estruturas de poder cultural. Dito de outra maneira, a nação nunca foi um ponto ímpar de identificação e união. Escondem-se neste discurso três questões centrais. A primeira é que muitas das nações modernas se constituíram pela conquista e unificação violenta de diversas culturas. Segundo que elas são sempre compostas por diferentes grupos étnicos e de gênero. Por fim, grande parte destas nações ocidentais modernas exerceram diversas formas de hegemonia cultural sobre a cultura dos colonizados. Assim, o que propõe Stuart Hall é que passemos a pensar as culturas nacionais, e aqui se nota que ele opta por não usar a palavra nação, como dispositivo discursivo que representa a diferença como unidade ou identidade. Em outras palavras, passar a compreender as nações modernas como híbridos culturais. Se passamos a compreender estas categorias a partir da leitura proposta por Stuart Hall, nos perguntamos: o que, então, veio a deslocar as identidades nacionais do século XX? Para nosso autor, a resposta seria um "complexo de processos e forças de mudança, que, por conveniência, pode ser sintetizado sob o termo globalização" (ibid, p.39).

A globalização apresentaria, no argumento de Hall, três possíveis consequências sobre as identidades culturais. A primeira seria a desintegração das identidades nacionais como resultado de homogeneização cultural do pós-moderno global. A segunda seria o reforço de algumas identidades nacionais e locais como forma de resistência aos efeitos globalizantes deste processo. E, por fim, o declínio das identidades nacionais com o surgimento de novas identidades híbridas em seu lugar. O que se coloca como condição de análise destas hipóteses é a compreensão de que, embora esteja dentro da lógica de compressão espaço-tempo, a globalização caminha a par de um reforçamento de identidades locais. Contudo, ela é um processo desigual e que se orienta pela sua própria "geometria de poder", retendo aspectos de dominação global ocidental. No que se refere às identidades culturais do sujeito, constata-se que emergem por todas as partes identidades culturais que não são fixas. Mas identidades que transitam e suspendem-se em diferentes posições. Buscando traduzir "aquelas formações de identidade que atravessam e intersectam as fronteiras naturais, compostas por pessoas que foram dispersadas para sempre de sua terra natal" e que ao manter vínculo com seus locais de origem e suas tradições não mantêm a ilusão de um retorno ao passado. Assim, Stuart Hall encerra sua linha argumentativa considerando que: 


\begin{abstract}
“(...)a globalização não parece estar produzindo nem o triunfo do "global" nem a persistência, em sua velha forma nacionalista, do "local". Os deslocamentos ou desvios da globalização mostram-se, afinal, mais variados e mais contraditórios do que sugerem seus protagonistas ou seus oponentes. Entretanto, isto também sugere que, embora alimentada, sob muitos aspectos, pelo Ocidente, a globalização pode acabar sendo parte daquele lento e desigual, mas continuado, descentramento do mesmo" (ibid, p. 56).
\end{abstract}

\title{
Diálogos com Paul Gilroy.
}

Propõe-se agora uma reflexão que busca dar conta de colocar no centro da discussão as opções metodológicas do autor para a abordagem do problema. Além disso, busca-se discutir e lançar hipóteses de como Hall compreenderia o debate de raça no momento histórico do pósmodernismo global. Olha-se também para a contribuição que a ideia de diáspora poderia trazer à análise da conjuntura social que se estende desde a data de publicação do livro até os dias de hoje. Para tal exercício imaginativo, buscaremos em Paul Gilroy alguns contrapontos de argumentos metodológicos que nos ajudem a trabalhar questões relativas à identidade, modernidade, questão racial e novas chaves de leitura para um mesmo problema.

Stuart Hall, um intelectual jamaicano, e que fez boa parte de sua formação acadêmica na Inglaterra, consegue construir um amplo alcance de suas ideias e de debate a partir da reflexão de outros autores. Considerado um dos fundadores dos Estudos Culturais nas décadas de 1960-1970, ele abrange diálogo com influências marxistas, como Raymond Williams, por exemplo, além de dialogar com contemporâneos do século XXI, como David Harvey e Anthony Giddens. O debate se dá transnacionalmente, assim como sua trajetória pessoal e profissional. A sua chave de entrada no debate da identidade se dá pelo meio histórico e pela construção de categorias que permitem articular e compreender as concepções de sujeitos ao longo da linha histórica. Entretanto, a leitura dessas categorias, embora sejam arquétipos para construção de conceitos mais amplos, nos permitem inferir um pensamento linear de história e que se cumpre a partir de um ideal de modernidade que se coloca a partir de uma construção ocidental europeia.

Hall observa na identidade individual um propulsor e receptor da modernidade, ou seja, o indivíduo como unidade central de análise e que, na contemporaneidade, se fragmenta e se torna cada vez mais reflexivo. Esta unidade de análise remonta à composição individual formada a partir de montagens de espaços autônomos da modernidade (ver apêndice). Contudo, seria essa fragmentação um índice exclusivo de caracterização deste período temporal específico ou, em outras palavras, um estágio histórico? Estes espaços autônomos que se relacionam são características típicas de um momento histórico? Paul Gilroy afirma que a noção 
de historicialidade é fruto da própria modernidade à medida em que supõe uma política do tempo. Em outras palavras, se projeta a maneira que ampara a modernidade e seu projeto político. O que afirma Gilroy, e em certa medida Hall, é que "universalidade, razão e progresso, modernidade e ilustração [...] foram as pedras fundamentais de toda a mentalidade conquistadora ocidental" (GILROY, 2007, p.93). Entretanto, tem-se a percepção que o argumento de Hall vale-se de categorias tipicamente ocidentais como marcos que delimitam a transição entre tipos de sujeitos, tipicamente eurocentrados. Entretanto, ambos apontam para o fenômeno da diáspora como uma possível ferramenta metodológica para a construção de novas formas de interpretação social.

Hall vê a diáspora como trânsito de pessoas, em seu maior conjunto negras, e ideias que tornam as identidades múltiplas, "onde junto com os elos que as ligam à uma ilha de origem específica há outras forças específicas" (HALL, 2003, p.27). Este fenômeno confere a sensação moderna de "des-locamento" (HALL, 2003) e baseia-se no conceito de différance de Derrida. Este, por sua vez, elimina os binarismos que opõem eu x outro e o dentro x fora. Gilroy vê na diáspora uma alternativa de releitura da história e dos processos que se convencionou chamar de modernidade, já que a própria história rejeita "a noção popular de ações naturais espontaneamente dotadas de uma consciência de si próprias". A noção de história não é, portanto, intrinsecamente dotada de especificidades essencializantes. A diáspora, portanto, surge como um novo "cronótropo" que poderia balizar uma teoria negra que fosse "menos intimidada pelos limites e integridades dos Estados-nações modernos" (GILROY, 2012). Para esta alternativa metodológica, Gilroy seleciona a imagem do navio para conceituar e teorizar sistemas vivos, microculturais e micropolíticos em movimento que se pautam pela circulação de ideias e ativistas, bem como panfletos, livros, registros fonográficos e coros. Esta escolha analítica aponta para novas possibilidades de compreensões e interpretações históricas e sociológicas. A justificativa para tal assertiva se dá, pois, ao "subir a bordo, por assim dizer, oferece um meio para reconceituar a relação ortodoxa entre a modernidade e o que é tomado como sua pré-história" (ibid, p. 61). A diáspora, ou fluxo do Atlântico Negro, como denomina Gilroy, romperia com o "foco dogmático" sobre a dinâmica nacional distinta que caracterizou tão grande fração do pensamento cultural euro-americano. Além disso, colocaria em relevo o caráter intercultural que já se forma bem antes daquilo que se chama de pós-moderno global. Em suma, a leitura social-histórica via diáspora nos permitiria ultrapassar as essencializantes leituras nacionais e nacionalistas e o que Gilroy sugere é que: 
“os historiadores culturais poderiam assumir o Atlântico como uma unidade de análise única e complexa em suas discussões do mundo moderno e utilizá-la para produzir uma perspectiva transnacional e intercultural. [Assim] a história do Atlântico Negro propicia um meio para reexaminar os problemas da nacionalidade, posicionamento, identidade e memória histórica" (ibid, p. 57-59).

Uma possível leitura deste argumento de Gilroy é a compreensão de que a constituição e a representação do sujeito nunca foram unas e indivisíveis. Haveria uma exceção à medida em que se entendesse a categoria do "sujeito do Iluminismo" ou o "sujeito sociológico" como dispositivos discursivos, subvertendo o argumento de Hall de possibilidades de compreender certas mudanças na questão da identidade por estas categorias. Aqui os argumentos de ambos os autores passam a ser lidos a partir da questão da diáspora frente ao "pós-moderno global" trabalhando possibilidades de interpretação da leitura sobre questões como identidade e raça. As questões que nortearão esta etapa serão: as identidades em algum momento foram centradas ou a metodologia da diáspora pode nos fazer rever o argumento de Hall? Como os autores, então, entendem a raça a partir de suas leituras sobre modernidade?

Stuart Hall, como se afirmou até aqui neste trabalho, enxerga, no período que denomina pós-moderno global, uma nova articulação das "políticas de fragmentação ou pluralização das identidades". Indiretamente, o autor jamaicano afirma então, que não se possui mais uma cédula identitária central que caracterize o indivíduo. As velhas categorias de identidade não produzem mais os mesmos efeitos de representação que outrora produziram e não constroem mais o discurso de coesão e unificação. À nossa leitura, Hall, como buscou-se ilustrar no apêndice, trabalha as categorias identitárias na modernidade como espaços (cédulas) de representação pela cultura e que se inter-relacionam, mas não se misturam, sejam elas a partir de gênero, nacionalidade ou raça. Como ele mesmo afirma, o descentramento das cédulas de identidades "abre caminhos para novos espaços de contestação, [uma] oportunidade estratégica para a intervenção no campo da cultura popular" (HALL, 2003, p.337). Este descentramento produz, portanto, a celebração móvel da identidade, formada e transformada continuamente pelos sistemas culturais que passam a ser interpelados, produzindo, por vezes, novos tipos de relações entre chaves de representação de identidade. Gilroy, em nossa leitura, distancia-se de Hall ao refletir sobre tal questão.

Gilroy, em $O$ Atlântico negro, mais precisamente no segundo capítulo, onde discute o espaço do Atlântico como contracultura da modernidade, aponta para uma reflexão interessante e que dialoga com o autor da obra resenhada: “Até que ponto o recente entusiasmo internacional pelos estudos culturais é gerado por suas associações profundas com a Inglaterra e as ideias de 
anglicidade?" (GILROY, 2012, p.39). Dito de outra maneira, até que ponto a análise de Hall vale-se de categorias eurocentradas de reflexão a partir da chave da cultura? Continua, o autor:

\footnotetext{
"Somos constantemente informados que compartilhar uma identidade é o mesmo que estar vinculado nos níveis mais fundamentais: nacional, "racial", étnico, regional e local. Ela circunscreve as divisões e os subconjuntos em nossas vidas sociais e ajuda a definir as fronteiras entre nossas tentativas locais e irregulares de dar sentido ao mundo. Nunca se fala de uma identidade humana" (GILROY, 2007, p. 124).
}

Somado a estes argumentos, o potencial metodológico e explicativo da diáspora constituiria importante modo de se pensar a questão da identidade. Esta, segundo este autor, nos ajudaria compreender "a formação daquele pronome perigoso: nós" a partir do cálculo da relação entre identidade e diferença como uma operação intrinsecamente política. Assim, a identidade se faz, centralmente na modernidade europeia, uma questão de poder e autoridade quando grupos procuram se realizar de maneira política. Exemplos são os projetos Iluministas de esclarecimento e razão. Tal operação acarreta na produção da identidade como uma "coisa a ser possuída e ostentada" e "não um processo contínuo de construção do eu e de interação social". A identidade para Gilroy, munido da metodologia diaspórica, seria um conjunto de características sociais que se relacionam nas experiências práticas de identificação (ou de representação, para Hall), simultâneas ou não, contraditórias ou não e que sempre concorreram para a formação de um indivíduo complexo em sua magnitude e que não seria divisível em grupos culturais restritos (ver apêndice). Em suma, este autor propõe que repensemos e recontextualizemos a modernidade e suas categorias. A leitura sobre a categoria raça, então, sofreria uma importante transformação e que se difere entre os argumentos de Hall e Gilroy.

Stuart Hall, ao argumentar em direção ao descentramento de identidades e a partir da perda de unidade do caráter identitário do sujeito do Iluminismo, indica a dificuldade em se unificar a identidade nacional em torno da raça, apesar desta ser produto daquela. $\mathrm{O}$ empecilho se dá à medida em que a categoria raça não se constrói como categoria biológica ou genética que possua validade científica. Raça, prossegue o autor,

\footnotetext{
"é uma categoria discursiva e não uma categoria biológica. Isto é, ela é categoria organizadora daquelas formas de falar, daqueles sistemas de representação e práticas sociais (discursos) que utilizam um conjunto frouxo, frequentemente pouco específico, de diferenças em termos de características físicas [...] como marcas simbólicas, a fim de diferenciar socialmente um grupo de outro" (HALL, 2015, p. 37).
}

Raça, a partir da leitura de Hall, assume em sua construção discursiva a forma de significante deslizante (HALL, 2003) e assume para si um dos principais fatores organizatórios 
dos grandes sistemas classificatórios para as sociedades humanas. Assim, ao dotar-se também daquilo que o autor chama de significado flutuante, a categoria raça se articularia pelo princípio da linguagem, que se escoraria em relações mutáveis de diferenças. Desta maneira, significantes e significados se refeririam ao conceito e sistemas de classificação de cultura. A diferença, ao formar-se nessa relação, constrói-se em um tipo de existência anômala adquirindo sentido e tornando-se fatores de cultura humana e de regulação de condutas quando se organiza dentro da linguagem e do discurso (HALL, 2003). Em suma, a raça, como significante discursivo, constituiria um sistema de equivalência entre natureza e cultura somado às características de representação por aparências físicas. A política, então, contra o racismo se constituiria na política da crítica, não existindo, portanto, raça e racismo fora do discurso ${ }^{3}$.

A análise de Gilroy se mostra severamente crítica "aos estudos culturais ingleses e afroamericanos marcados por perspectivas etnocêntrica e nacionalista" (SANTOS, 2002). Como afirma Santos, este autor

\begin{abstract}
"promove igualmente uma avaliação crítica do uso das noções de etnia no interior destes estudos, ao mesmo tempo em que se opõe à falsa idéia de que a cultura sempre flui em padrões correspondentes à fronteira do Estado-nação. Do ponto de vista do autor, a relação entre nacionalidade e etnia foi apoiada retoricamente pelo inclusivismo cultural que enfatiza o sentido absoluto da diferença étnica entre os indivíduos em detrimento das suas experiências social e histórica" (SANTOS, 2002, p. 276).
\end{abstract}

De maneira distinta de Hall, Gilroy pensa a questão raça com certa distância da chave cultural. A raça em si não faria sentido fora de um discurso eurocêntrico de política de poder e controle. Os processos de racialização são frutos de produção da modernidade europeia e da construção do ideário dos Estados-nações do século XIX e de seus parâmetros impostos nos esforços de racionalidade iluminista. A categoria raça, portanto, se produzira fora das experiências sociais e históricas dos próprios grupos racializados. Gilroy aponta a curiosidade de o próprio termo ter sido empregado no século XIX, antes da consolidação do racismo científico, quase no mesmo sentido em que a palavra cultura é empregada hoje (GILROY, 2012, p. 42). Além disso, o portador da categoria raça, e o que se delimita por ela, são os grupos que não a inventam. Desconectam-se de grupos negros as experiências históricas e sociais que poderiam balizar uma nova perspectiva metodológica sobre a construção de identidades e cultura. "A consagração da raça colocou essas tradições à margem das histórias oficiais da modernidade" (GILROY, 2007, p.30). Essas tradições construiriam então uma abertura para se

${ }^{3}$ revistazcultural.pacc.ufrj.br/raça-o-significante-flutuante/ - acessado em 11/11/2016 às 22:41 
pensar a diversidade e o descentramento que, supostamente, seriam características típicas de uma pós-modernidade global. Assim, "subir a bordo, por dizer, oferece um meio para reconceituar a relação ortodoxa entre a modernidade e o que é tomado como sua pré-história" (ibid, p.61). Além do mais fornece, como um dos primeiros "cronótopos" modernos, uma reconceituação "extranacional" e "transcultural" para pensarmos as categorias forjadas pelo arquétipo de modernidade europeia iluminista, incluindo raça.

Comparativamente, as linhas argumentativas se distanciam quanto à possibilidade e a maneira de construírem o mesmo momento histórico a partir de chaves de leitura diferenciadas. Hall alicerça a categoria raça como um dispositivo discursivo que constrói e une sujeitos a partir de representações identitárias. Seu desenrolar implica em olhar a representação, inclusive a racial, ancorada no complexo cultural e que situa, centralmente, as décadas de 1960/1970, como um marco de ruptura e descentramento com as identidades postas pela modernidade. A raça é lida a partir da linguagem e da cultura. De certa forma, o que Hall nos afirma é que a própria representação sob a chave racial sofre alteração, ela não mais articula sujeitos e identidades do mesmo modo que no período moderno. Gilroy inicia seu argumento por este ponto que aquele autor nos conduz.

O ponto de partida, então, é afirmar que a argumentação que indica o conceito de pósmodernismo como uma transição histórica deve ser repensada quando se flexiona a possibilidade "de que grande parte do que é identificado como pós-moderno possa ter sido pressagiado ou prefigurado nos contornos da própria modernidade". Dito de outra maneira, a história e cultura da diáspora africana, a prática da escravidão racial ou as narrativas de conquista imperial europeia podem demandar a reperiodização destes momentos históricos e eliminação de certas categorias, como a racial. Em traços fortes, o argumento de Gilroy caminha na direção de afirmar a impossibilidade de existência da "raça" como conceito e, até mesmo, como representação, embora entenda que a adoção do ser negro possa ser formas de lutas políticas de resistência. Assim, a raça é uma tática política moderna. Raça não seria representação à priori e nem de relações culturais entre grupos distintos, como no argumento de Stuart Hall. Seria, pois, uma imposição de um grupo sobre outro, como estratégia de dominação e subordinação e que devemos renunciá-las em busca de pensarmos a humanidade não mais subdivida em raças.

\section{Conclusão}


Buscou-se neste ensaio reconstruir o argumento central de Stuart Hall exposto em $A$ Identidade Cultural na Pós-Modernidade. De maneira quase pedagógica, tentamos traçar os elos entre argumentos e expô-los de forma que pudéssemos construir um diálogo crítico sobre modernidade, identidade e raça. Este se construiu a partir da leitura de alguns textos produzidos por Paul Gilroy, principalmente a partir do argumento de uma metodologia transformadora que pudesse nos balizar a partir da diáspora africana, também pensada por Hall. Parece-nos que ambas as discussões partem de pressupostos e de construções teóricas distintas. Enquanto Hall “imobiliza" as construções identitárias, incluindo raça, a partir da noção de nação, que se desagrega com o passar do tempo, Gilroy busca construí-las já em movimento, rompendo com alguns estatutos deque o primeiro autor se vale para discutir o tema. A diáspora para Gilroy seria a melhor representação para o modo como a modernidade foi construída, pois "abandona" a centralidade nacional. A nosso ver, essa é uma das boas pistas para pensarmos o modo como raça e outras possíveis identidades se construíram em países marcados pela experiência colonial, como é o caso brasileiro. Isso pois grande parte dos autores que compõem os cursos sobre pensamento social brasileiro se depararam em algum momento de reflexão com o problema sobre o que é ser moderno em um país periférico. Não raramente a resposta dada a esse tipo de questionamento foi a ausência de uma vida democrática no país ou um descompasso com as formas modernas de se existir no panteão das nações.

O descompasso ou a ausência de requisitos necessários para compor uma modernidade brasileira, por exemplo, ao estilo que se imaginou na Europa, passa centralmente pelo modo como "tipificamos" um modelo moderno. A nação, mesmo a despeito de sua imposição violenta, em nossa leitura dos argumentos de Hall, carrega consigo alguns elementos que, indiretamente, remetem-se à noção de autonomia, enquanto possibilidade de manter-se autonomamente. Com as identidades, já que elas estão em relação direta com a nação, não poderia ser diferente. Um britânico seria portador da identidade britânica, mas poderia portar também a identidade branca, protestante e masculina. De certa forma, o que Hall sugere é que a pós-modernidade realoca esta ideia de autonomia, fazendo com que estas maneiras de identificação não se completem em si mesmas e que possam ser fragmentadas relacionalmente. Ser um homem, britânico e protestante comporta agora novas dimensões que não são similares a ser um homem, a ser um britânico e a ser um protestante. A modernidade, portanto, seria um processo que balizaria as identidades como pequenos "estanques" autônomos. A pósmodernidade intensificaria a relação entre eles, de modo que a autonomia fosse minada pelos 
processos de globalização, não mais sendo possível tomar as categorias identitárias isoladamente.

O principal desafio dessa análise encontra-se justamente no argumento de Gilroy: é possível omitirmos que a modernidade construída por Hall tem bases fortemente eurocentradas? Se sim, resolve-se o problema de analisar o caso brasileiro e passamos a adotar um sentido único à modernidade. Se não, como é o que defendemos, a proposta de $O$ Atlântico Negro traz importantes contribuições para pensarmos, inclusive, os dilemas da construção da nação e de identidades em países marcados pela experiência colonizadora e escravocrata. Dito de outra maneira, a análise do autor londrino complexifica as perguntas construídas em torno do debate, já que considera uma miríade de sujeitos e processos oriundos destas experiências constituintes da própria modernidade. Assim, identificar-se enquanto negro ou branco, na sociedade brasileira, não pode ser feito de maneira autônoma à situação colonial ou escravocrata, referindo-se apenas ao status obtido via Estado-Nação. Portanto, essa fragmentação identitária não é produto de um processo novo ao qual designamos por globalização, mas sim um problema epistemológico que desconsidera as experiências transatlânticas vividas, principalmente, por países que tiveram de lidar com o problema da colonização e/ou da escravidão.

Um ponto de distanciamento de nossa análise e o olhar de Gilroy se refere ao fato de acreditarmos que, embora seja uma "tática política moderna", "raça" se construiu histórica e socialmente articulando sujeitos a partir de representações que faziam de si e dos outros. A própria ideia de raça se construiu, e aqui corroboramos o argumento de Hall, como um "significante flutuante", ou seja, como "um dos principais conceitos que organiza os grandes sistemas classificatórios da diferença que operam em sociedades humanas" (HALL, 2015a). Desta maneira, impõe-se a nós, cientistas sociais, estudarmos esta ideia como uma construção social operativa tanto no terreno da cultura, como no plano discursivo e não somente como um dispositivo político. Seja em sua dimensão "nativa" ou em sua dimensão "analítica" (GUIMARÃES, 2003), de preferência combinando-as, cabe nos indagar o modo como raça e identidade são utilizadas em nossos contextos históricos e sociais específicos.

\section{Referências bibliográficas}

COSTA, Sérgio. Desprovincializando a sociologia: contribuição pós-colonial. Revista Brasileira de Ciências Sociais, São Paulo, v.21 n 60, fev. 2006. 
GOMES, Geam Karlo. Identidade em trânsito: a experiência diaspórica em nação crioula. Revista de Estudos Linguísticos, Literários, Culturais e da Contemporaneidade - Número Especial 18b, mar. 2016 - Com artigos, resumos e comunicações do CONEAB, 2015.

GILROY, Paul. Entre campos: nações, cultura e o fascínio da raça. São Paulo: Annablume, 2007.

O Atlântico negro: modernidade e dupla consciência. São Paulo: Editora 34,

2012.

GUIMARÃES, Antônio Sérgio. Como trabalhar com "raça" em sociologia. Educação e Pesquisa, São Paulo, v.29, n.1, p. 93-107, jan./jun. 2003.

HALL, Stuart. A identidade cultural na pós-modernidade. Rio de Janeiro: Lamparina, 2015. UFMG, 2003

Da diáspora: identidades e mediações culturais. Belo Horizonte: Editora . Raça, o significante flutuante. Tradução de Liv Sovik, em colaboração com Katia Santos. Rio de Janeiro. Revista Z Cultural, n.2, ano 8, 2015a

ORTIZ, Renato. Mundialização e cultura. São Paulo: Brasiliense, 2013.

SANTOS, Eufrázia C. Menezes. Resenha de O Atlântico negro. In: Revista de Antropologia, São Paulo, USP, 2002.

VILAR, Pierre. La história de España. Madri: Editora Grijalbo, 1978.

\section{APÊNDICE}

Composição do indivíduo na obra de Stuart Hall no período do pós-moderno global em nossa leitura:

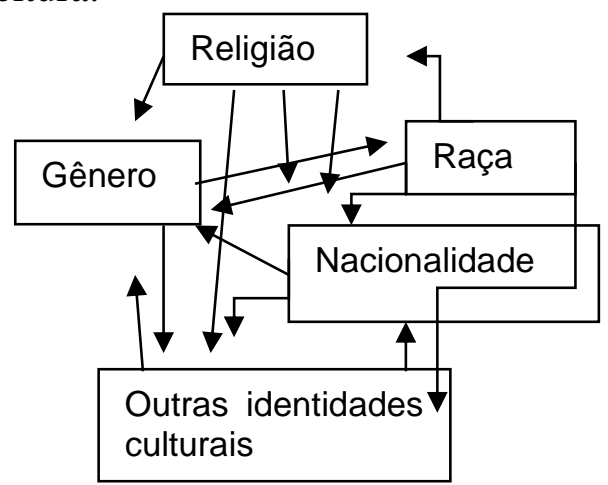

Composição do indivíduo na obra de Paul Gilroy a partir de experiências práticas diaspóricas como um constructo de identidade humana complexa e relacional em nossa leitura: 


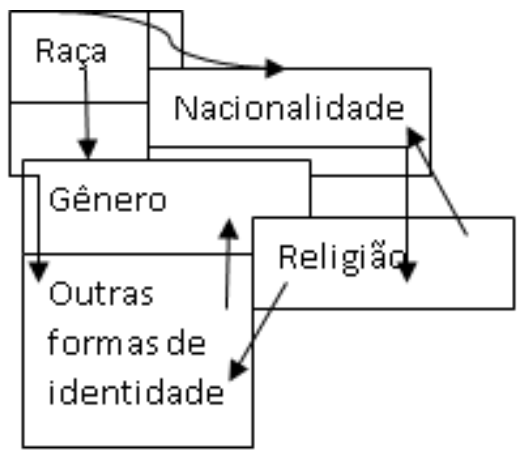

Recebido em: Abril de 2018 Aprovado em: Julho de 2018 